\title{
Pandemic resilience and health systems preparedness: lessons from COVID-19 for the twenty-first century
}

\author{
T. Sundararaman ${ }^{1}$ (D) . V. R. Muraleedharan ${ }^{1}$ (D) $\cdot$ Alok Ranjan $^{2}$ (D)
}

Accepted: 20 November 2020 / Published online: 6 January 2021

(c) Institute for Social and Economic Change 2021

\begin{abstract}
The pandemic of COVID-19 disease has acted like a stress test on every aspect of life, but particularly exposed weaknesses of health systems design and capacity. There have been similar pandemics in the past, and the threat of more frequent future pandemics in the twenty-first century is real. It is therefore important to learn the right lessons with regard to health systems preparedness and resilience. The five design features that this paper discusses are related to the organization of primary care services, planned surge capacity in secondary and tertiary care, a robust disease surveillance system that is integrated with the health management information system, adequate domestic capacity in being able to innovate and scale up production and logistics of much needed medical products and a governance approach that recognizes the importance of the health systems being able to continuously learn and adapt to meet changing needs. In addition to this, the organizational capacity of the system to deliver required services would need more investment in financial resources, and a suitable health human resource policy.
\end{abstract}

Keywords Health systems resilience $\cdot$ COVID-19 $\cdot$ India

\section{Introduction}

Severe acute respiratory syndrome coronavirus-2 (SARS-CoV-2) is a new virus causing a disease which has been termed Coronavirus Disease 2019 or COVID-19. At the time of writing, this virus has infected 17 million individuals across 216 nations with 6.7 lakhs fatalities (WHO 2020a, July 31st, 2020). COVID-19 pandemic has acted like a stress test

T. Sundararaman

sundar2016@gmail.com

V. R. Muraleedharan

vrm@iitm.ac.in

Alok Ranjan

alokranjancmc@gmail.com

1 Department of Humanities and Social Sciences, Centre for Technology and Policy, Indian Institute of Technology-Madras, Chennai, India

2 Department of Humanities and Social Sciences, Indian Institute of Technology-Madras, Chennai, India 
on every aspect of human life ranging from health systems which are most immediately affected by the entire social and economic front (The Economist 2020a). All countries have struggled to respond to the pandemic in different ways. However, only a few have succeeded in avoiding the economic lockdowns as well as keeping levels of infection and mortality low.

COVID-19 is not a "black swan" event (highly improbable and highly unpredictable event). Before this, the world has seen the influenza pandemic of 2009 (H1N1pdh09 virus, with 5.7 lakh deaths), the 1968 pandemic (H3N2 virus, with 1 million deaths), the flu pandemic of 1957-1958 (H2N2 virus, with 1.1 million deaths) and, the most fatal of these, the 1918 flu pandemic (H1N1 virus, with 50 million deaths) (CDC 2018). Recent evidence suggests that pandemics are going to be more frequent in future. The outbreak of Ebola virus diseases and Zika virus and the H1N1 within just the last decade is indicative of this trend.

One of the contemporary arguments, a complacent one, narrates that COVID-19 pandemic is once-in-a-lifetime event and most of the countries were unprepared to handle the crisis, and so not to be blamed for their failures. However, some of the countries which have been successful in containing the pandemic, with relatively less mortality and negative economic consequences, like South Korea, Mongolia, Vietnam and even China, have learnt and addressed the weaknesses revealed by SARS, 2003, and MERS, 2015, outbreak (Normile 2020; UN 2020). Within India, Kerala's learning from the Nipah virus outbreak is such an example.

In May 2020, the World Health Assembly was held as a virtual event for only one day and it had just one resolution-WHA 73-that pertained to the COVID-19 pandemic and the response to it. This resolution called for international organizations and other relevant stakeholders "to support countries in health system strengthening" (O.P.8.1) and to assist and continue to call upon all States' Parties to take the actions according to the provisions of the "International Health regulations", including by providing all necessary support to countries for building, strengthening and maintaining their capacities to fully comply with the IHR (O.P.9.3) (WHO 2020b). Under the International Health Regulations, there is "a global commitment to identify, investigate, assess and respond to public health events" (WHO 2008). Though much attention in this World Health Assembly meeting was given to WHO's alleged failures to respond to the outbreak at China, almost no attention was given to the even more important legally binding commitment that nation states and the WHO had made, under the International Health Regulations treaty, to keep health systems functional at the level of preparedness, required to manage pandemics.

In an increasingly globalizing world, the threat of recurrent pandemics must be seen as inevitable. This threat is partly due to the increase in international and domestic travel and trade that makes for a very rapid international spread of any highly infective pathogen. This threat also arises from increased encroachment and intervention in the bio-environment, leading to the emergence of new pathogens. Governments and global institutions must therefore give much importance to building "resilient healthcare systems" which can absorb the shock of such emergencies by learning from previous experience, and transforming itself, not only to respond to the pandemics but also being able to ensure continued provision of other essential health care services without interruption (Blanchet 2015). Health systems resilience has been defined as "the capacity of health actors, institutions, and populations to prepare for and effectively respond to crises; maintain core functions when a crisis hits; and, informed by lessons learned during the crisis, reorganise if conditions require it" (Kruk et al. 2015). Response to a crisis needs "both a vigorous public health response and a highly proactive and functioning 
health-care delivery system" (Kruk et al. 2015). Both these systems must work in concert during a crisis - and indeed they can do so only if designed such long before crisis strikes - which is the element of health systems preparedness.

There are different frameworks in which resilient health systems have been analysed. One recent framework (Hanefeld et al. 2018) advocates examining it in terms of three core dimensions: health information systems, health care financing and workforce issues and two cross-cutting ones-governance and values. This is broadly an adaptation of the six building blocks of the WHO Health Systems Framework (WHO 2007), and the $3+2$ dimensions are synonymous with four of the six. The additional concept of values in this framework adds on the political priority given to sustaining health response as well as the personal, professional and societal values or moral landscapes of the main actors. The two building blocks that this framework does not discuss, but which we think require a much larger emphasis, are access to technologies and the organization of services. Yet another framework described resilience as requiring three preconditionsglobal solidarity, legal frameworks and workforce policies, and being characterized by five elements of which one termed "self-regulation" is further elaborated as the ability to quickly identify and isolate a threat and target resources to it, minimizing disruption to provision of essential health services during crisis, and the availability, in particular locations, of excess or redundant capacity that can quickly be brought online (Kruk et al. 2015). The capacity to respond to a pandemic, this paper contends, depends on specific design dimensions of the organization of services-some long term and some as part of the immediate response. The other characteristics of resilience in this framework are awareness, which depends on its surveillance and information systems, diversity, which depends on the range of services available in its primary health care system, and finally integration, and adaptiveness that depends largely on the nature of governance. Both frameworks stress community engagement.

The current paper draws and adapts from these two frameworks to focus on five important design dimensions of resilient health care systems and two important preconditions. In focussing on design, we are making the point that while all health systems are always committed to having in place the six building blocks, resilience would be determined by some key design characteristics of each of the building block that makes them more aware and adaptive. The two preconditions are of course financing and human resource policies in place. Thus, the framework we use goes back to the six building blocks of the WHO framework - the organization of health services, health information, access to technologies, governance and leadership, human resources for health and the financing of health care. Whereas the last two are discussed as preconditions, in the first four we are focussing on specific design gaps between what exists today and what is required for resilience.

With respect to the organization of health services, there are two aspects of design that we draw attention to-an adequately designed primary health care system and an inbuilt surge capacity at the secondary and tertiary level. With respect to health information building block, our emphasis is in the design of good disease surveillance systems and their integration with health management information systems. In access to technologies, the design element discussed is the ability for rapid development of medical products and being able to take procurement and manufacture of new products to scale in a very short time period. Earlier frameworks on resilience do not engage with this element, but as this pandemic shows, nations which have been able to get their testing kits in place faster, like South Korea, have done much better. With respect to governance, the one "design" aspect of governance that we draw attention to is the ability to generate and use evidence and learn from past experiences to keep adapting the system. 


\section{Adequately designed primary health care}

In India, primary health care provides very selective range of services related to maternal and child health, immunization, malaria, tuberculosis, HIV and leprosy. With the epidemiological and demographic transition, the disease burden of non-communicable diseases (NCDs) has increased significantly, but there are minimal primary care services for the same. Even with regard to communicable diseases, the focus has been only on a few diseases. But diversity in what a health system addresses is an important element of resilience. And so is being close to the community-both in terms of distances involved and in terms of relationships between providers and the community. Such an organization of primary health care will be able to cater to over $70 \%$ of health care needs near to the community and therefore can command the trust and confidence of the population in the midst of a crisis. Effective primary health care also requires a very good link between primary care providers and higher levels of care-for often diagnosis and treatment, planning will require specialist consultations-but both early identification and subsequent follow-up require primary care providers who are trained and supported to do so. The design of "continuity of care" across levels of care is an important element of the required organization. Resilient health care systems are also systems that are able to retain all essential health services without disruption even when having to respond to a pandemic. Such "continuity of care" requires the primary care services to be close to community and providing a much more comprehensive package of services. Both types of continuity of care require impeccable logistics that ensures an uninterrupted supply of essential medicines despite the very many barriers that the crisis creates.

The Ayushman Bharat's second pillar Health and Wellness Centres, launched in 2018, is designed along these lines, but its take-off has been very slow. Its target was to reach 150,000 centres by 2022 , but it has reached only about 29,000 centres as of February 2020 (PIB 2020). And this slow take-off, as is discussed in more detail later, can be attributed to the two preconditions we discussed-the financial resources made available and the human resources policies that are in place.

The main reason why Kerala has done much better in its ability to contain the pandemic and reduce mortality is because of its robust primary health care system, which had been recently strengthened by a state government reform programme called the Aardram programme (Arafath 2020; Sadanandan 2020). Because of the high levels of trust and confidence, people came forward to identify themselves if they had COVID-19 symptoms or were contacts, leading to much better contact tracing. Because of the preexisting outreach programme, patients on home quarantine could be supported, elderly and vulnerable could be shielded, and patients with chronic illnesses could be homedelivered essential medicines without interruption. But in urban metropolis, where community outreach was weak, contact tracing was difficult and maintenance of other essential health services was almost impossible, except for those few who could buy their medicines in the local pharmacies and manage without medical support. This, as well as the large number of migrants returning from abroad, could perhaps partly explain the slow but definite increase in the transmission of COVID-19 in urban areas of Kerala during the month of July.

Another important design feature of effective primary health care that we can learn from Kerala is an imaginative health communication strategy that combines with effective forms of community engagement. In India, this would mean a much greater participation of the institutions of local self-government, as well as engagement of civil 
society organizations and community-based organizations in health communication and the provision of services.

International comparisons also indicate that though a good primary health care system is not by itself sufficient to ensure a better resilience, it is certainly essential for this purpose. In the developed world countries where such universal health care systems with comprehensive packages of primary health care services are available, as in the Scandinavian nations, New Zealand, Australia, Canada, Japan and South Korea have all done better in controlling the pandemic (Khun 2020; Normile 2020). In the developing world, countries like Vietnam, Cuba, Sri Lanka and Thailand which are known for relatively more universal health care systems with a strong emphasis on more comprehensive primary health care have also done better (Beech and Dean 2020; Augustin 2020; The Economist 2020b).

\section{Surge capacity}

The other major requirement for coping with pandemics is a public health system which has adequate "surge capacity" which can be defined as "the availability, in particular locations, of excess or redundant capacity that can quickly be brought online" (Kruk et al. 2015). This is important not only for pandemics but for all public health emergencies and situations where there is a sudden increase in demands for health care, usually used in the context of hospital care. This implies that what is required is a network of public hospitals with a planned excess of beds, staff and equipment, such that when faced with an emergency, the surge of cases could be managed (UN 2020). This surge of patients could also be managed by placing private hospitals under public authority - and indeed there are provisions in the Disaster Management Act that allow government to do so. Potentially, it could also be managed by "purchasing" additional capacity in the private sector, through government-funded insurance programmes or through other forms of contracting or commandeering.

The recent trends in public policy have been to minimize the role of public provision of services and shift the role of the government to purchasing care from private providers for meeting secondary and tertiary care needs. But when public health emergencies arise, such arrangements are not able to fill the gaps. The Prime Minister's Jan Arogya Yojana (PM-JAY) was introduced as a government-funded health insurance programme to provide coverage for secondary and tertiary care for those below the poverty line and in the unorganized sector. In the current pandemic, though a reimbursement package for COVID-19 was quickly included into the PM-JAY (Government of India 2020), few empanelled private hospitals have admitted or claimed reimbursement for the same (The Hindu 2020a). On the other hand, there was a closure of several private hospitals to safeguard themselves (Yamunan 2020), and those that provided services could be charging exorbitant amounts (Indian Express 2020). There were efforts to bring private hospitals under public authority, but these were soon given up as the necessary political will and administrative capacity was not in place. Some efforts were made to ask some of the private hospitals to reserve a proportion of the beds for treating COVID-19 and to cap the rates charged-but neither could be enforced effectively (The Hindu 2020b).

What the pandemic showed was that the medical response to a public health emergency is therefore almost completely dependent on public hospitals. However, public health services are currently designed on the basis of the minimum capacity that is required with the understanding that the rest of those seeking health care should go to the private sector. If the number of beds, equipment diagnostics and ambulance services in publicly owned 
secondary and tertiary care services are to be planned with adequate inbuilt surge capacity, public policy would have to acknowledge that all of health care, and not only preventive health care services, are global public goods. Building in redundant capacity is a design change, but to achieve this change, there has to be a shift in the values that the system is driven by.

One other pathway to rapid addition of capacity in times of crisis is extending partnerships with suitable not-for-profit private providers who have a track record of ethical practice, affordable care and working with marginalized sections. The success stories of harnessing the NGO sector for leprosy prevention and later for blindness control through cataract surgeries are well documented. Especially in the urban areas, the well-functioning NGOs should be nurtured and supported to continue to serve as an effective part of the health system. It is relevant to point out that such "not-for-profit" organizations have badly been hit by the pandemic and ensuing lockdowns and may have to be supported by the Government even to survive.

\section{Disease surveillance and health management information systems}

Regular diseases surveillance for emerging infectious diseases is critical for being able to respond to pandemics and to contain them early and mitigate their impact. Countries which have done better in handling COVID-19, for example South Korea and Vietnam, had good diseases surveillance system (Normile 2020). India had developed a reasonably effective Integrated Diseases Surveillance Program (IDSP), which was aimed to provide a weekly update about the disease-outbreaks; but it stopped providing such updates after February, when Government of India started a new portal for COIVD-19 update (Sundararaman 2020). An effective disease surveillance system reports not only sudden unusual health events, but also routine data on morbidity patterns from every health care provider. Thus, any usual spurt of cases of fever or other symptoms raises a local alert, leading to a timely and adequate response. These symptoms-based reports alert the local authorities, but require to be followed up by confirmatory tests done in a network of laboratories. When access to diagnostics is limited, as happens most commonly in more remote areas, the symptom-based reports of the IDSP identify suspected cases and deaths and are of considerable use in early identification of new chains of transmission and response to the same.

Such a robust digitized disease surveillance system that is seamlessly integrated with health management information systems is an essential element of building resilience. The real-time health information provided by such a system is invaluable not only for providing early warnings of an outbreak but also for tracking the spread of the epidemic, forecasting and preparing the health care system for the surge (Kruk 2008). Further, it identifies areas where access to other essential health services have been compromised and need to be urgently responded to. Current health management information systems, however, have many gaps. One problem is the lack of inter-operability between the IDSP's digital platform and the HMIS. Further in most states, the HMIS does not have private sector data. Further, neither disease surveillance system nor HMIS collects data that can be disaggregated for understanding disease relationship with inequity-like the migrant worker, or the elderly or other vulnerable groups who could be a potential source of transmission for the diseases.

Countries that have relatively better health information systems, like the National Health Services (NHS) in UK or the Scandinavian countries, were more responsive to the COVID-19. They could do early studies of patterns of disease spread, from their 
well-maintained patient records, and use this to identify the chains of transmission and determine risk factors for the COVID deaths in their country (Lusignan et al. 2020; The Economist 2020c).

There is also a need to integrate HMIS with other sectors data. For example, there is a need to integrate health care data with the measures of environment and climate change and forecasting of extreme weather, as to study the impact of this on both chronic illness and diseases outbreak (Mayhew and Hanefeld 2014). Similarly, we also need integration of economic data with the health system, for example, impact of wide range of economic events like changes in trade policy or economic crisis like the global financial crisis of 2009, on the health outcomes and health systems performance (Karanikolos et al. 2013). One of the challenges we face in these data is related to the time frame of data collection and issues of integration. Health data often lag a year or so behind, whereas economic data are more real time (McKee et al. 2012).

While handling the shocks or emergencies, the information required may be different from the data required for routine purposes (Bell et al. 2012). To address this issue, there is a greater need for investment in human resource training, innovative and userfriendly technology, preferably open source, and good governance.

This could be seen in the case of countries like Germany when its laboratories were ready to do more than 50,000 tests per day by mid of February, even when COVID was largely localized to China only, and by doing this early forecasting, they were "maximally prepared" (The Economic Times 2020).

\section{Promote domestic capacity for medical technology}

One of the important and least discussed aspects of building resilient health care systems is the ability to manage global and local supply chains for essential medical products. One dimension of this is that the public health systems of each state must have robust systems for procurement and distribution. Few states in India, notably Tamil Nadu, Rajasthan and Kerala, have such systems in place-but for others managing the logistics would be a struggle.

But the other aspect of resilience that this pandemic has drawn public attention to is the need for countries to invest in developing domestic manufacturing capacity and for building the innovation ecosystems required for health security and self-reliance. Such domestic capacity will include capacity to provide sufficient quantities of necessary medicines, diagnostics, devices, vaccines and personal protective equipment that the country needs. COVID-19 has shown us that in a crisis, global supply chains are unreliable and inequitable. The European Union (EU) and the USA are likely to enter into advanced marketing commitments that will corner supplies of any new vaccine or medicine even before they are manufactured (Aljazeera 2020; The Guardian 2020). But India has a reputation of the pharmacy of the developing world, because it could manufacture all essential medicines and diagnostics that not only India, but the entire world needs-but at far more affordable costs than the industrialized nations. We need to understand what went wrong during this pandemic and why we had to import almost all the diagnostics, drugs and PPE that the country needed. This would help us plan to urgently rebuild our domestic capacity in innovation and domestic manufacture of essential medical products. 


\section{Governance}

Governance is one vital aspect of handling health care emergencies, and it is a cross-cutting dimension of health system functions (Gostin and Friedman 2015). Responding to the COVID-19 pandemic, the Indian government set up a command and control governance structure which falls under the National Disaster Management Authority, which falls under the jurisdiction of the Home Ministry. Though this could have been advantageous for addressing law and order measures related to the lockdown, such an institutional structure has limited understanding of health systems and more importantly fails to understand both the importance of community engagement and the need and ability to learn from multiple sources and past experience (Chandler et al. 2015). Observations from across countries indicate that those countries or regions which experienced the SARS epidemic, or the H1N1 epidemic or a Nipah virus outbreak, were better able to cope with the current pandemic than others because they learnt from the earlier epidemic. The relative success of China, Vietnam, Mongolia, Korea and Kerala (which had a Nipah virus outbreak) is attributed to having learning health systems (The Economist 2020b; Sadanandan 2020). Building learning health systems into governance of health is a design issue and requires attention to both institutional structures and processes that facilitate this. These are not built in a day, but once they are in place they are the institutional memory of past learnings that ensures that the current response is far more effective.

Apart from these five design dimensions of resilient health systems, there are two important preconditions that are essential for health systems preparedness. These preconditions are core requirements of resilience - and not so much a challenge of design, but of political will and public policy. These are human resources capacity and the funding and financing mechanisms. These are discussed below.

\section{Human resource capacity as a precondition of resilience}

Current COVID-19 exposes the shortages of a health care provider in India. Many of the public and private hospitals have reported shortages of health care providers even in urban areas, leave alone the countryside (Sharma 2020; Business Insider 2020). Scarcity of human resources is not an acute problem due to COVID-19, but through the long neglect by government policies. Over the years, government has relied more on contractualization of staff with "poor salary structure" which could not retain health care workers (Sundararaman 2020; Baru and Zafar 2020). COVID-19 also shows that role of the public sector is crucial in handing the health care emergency, where the private sector does not invest (Krishnan and Dasgupta 2020). Even in rural areas where public facilities struggle with shortage of health care provider, it is ASHAs, the frontline workers, who are handing the COVID-19 (Chatterjee 2020). Current pandemic is a wake-up call to fill all vacant posts in public health facilities, with an added focus on surge capacity to meet future health care emergencies.

\section{Funding and financing mechanism as a precondition of resilience}

India's health care system is underfunded. The government spends $1.3 \%$ of total GDP as public health expenditure, against $2.5 \%$ envisaged under National Health Policy 2017. This is one of the lowest in the world. Such underfinancing of public health systems leads to undermining the health security of the nation, and this in turn can lead to huge adverse 
impacts on the economy (Sundararaman et al. 2016). At the time of a crisis, the capacity to absorb a sudden increase in resources is limited. Both investment in infrastructure and investment in building up a workforce require to be done well before a crisis, and only if these are in place can a sudden increase in resources be absorbed. This is also true for building surge capacity (or planned redundancy) in government health facilities to meet the health care needs during the time of crisis (UN 2020).

Studies have shown that health care emergencies hamper the supply chain management of medicines and increase the out-of-pocket expenditure (OOPE) for the family (Karanikolos et al. 2013). Health systems response during Ebola virus diseases, in Sierra Leone and Liberia, was praised since they offered free services for people without Ebola (Oosterhoff et al. 2015). Public policy in India also called for free care for all patients coming to government hospitals. But due to shortages of consumables, and amenities, there were significant out-of-pocket expenditures even at the hospital. Those who had to go to private hospitals because of poor quality in the overcrowded government hospitals, or quite often due a lack of beds, had to pay exorbitant prices in the unregulated private sector. One of the main goals of public health systems is to ensure financial protection against the costs of health care-and this is most necessary during a pandemic when lockdowns have undermined or destroyed the livelihoods of millions. The financial protection against the costs of health care that the majority of the working people need and deserve calls for a much higher level of public health expenditure than is currently the case.

\section{Conclusion}

As of July end, the COVID-19 pandemic is still accelerating. However, there is hope that by the end of the year 2020, the pandemic would decline, both due to better control measures and due to increasing herd immunity levels. Already in the cities that saw the major outbreaks, considerable temporary additions in capacity are now no longer necessary. And there is always the promise that a vaccine would become available. Given the huge economic crisis and the demands on public expenditure to bolster economic growth in multiple sectors, there would be pressures to reduce public health expenditures. There may also be pressures to restrict increases in public health expenditure to vaccines against COVID19 and other forms of immediate pandemic response. But that would be a mistake. Many of the countries that have done well against the pandemic had learnt their lessons well from the earlier SARS pandemic or other major outbreaks and built up resilient health care systems that could face subsequent shocks much better. We need to do the same now. Every single one of the measures described above is an essential action that governments must take. But only if all of them are in place it is sufficient. Neither the health security of a nation, nor its economic growth and security can be assured without these measures. And for that reason, the entire package must be recognized as part of a global public good.

\section{References}

Aljazeera (2020) Race for virus vaccine could leave poor countries behind. https://www.aljazeera.com/ news/2020/06/race-virus-vaccine-leave-poor-countries-200618071819077.html. Accessed 30 July 2020 
Arafath Y (2020) Success of the Kerala model. https://www.telegraphindia.com/opinion/coronaviru s-kerala-success-with-covid-19-pandemic-is-because-of-its-understanding-of-the-idea-of-citizenshi p-shaped-by-its-high-level-of-literacy-and-secular-sensibilities/cid/1767508. Accessed 30 July 2020

Augustin Ed (2020) Cuba sets example with successful COVID-19 strategy. https://www.aljazeera.com/ news/2020/07/cuba-sets-successful-covid-19-strategy-200723105446283.html. Accessed 30 July 2020

Baru R, Zafar S (2020) Low wages, poor PPE: contractual healthcare workers face the worst of the pandemic. The Wire https://thewire.in/rights/health-workers-safety. Accessed 30 July 2020

Beech H, Dean A (2020) No one knows what thailand is doing right, but so far, it's working. The New York Times. https://www.nytimes.com/2020/07/16/world/asia/coronavirus-thailand-photos.html. Accessed 30 July 2020

Bell M, Warren A, Budd L (2012) Scales of governance: the role of surveillance in facilitating new diplomacy during the 2009-2010 H1N1 pandemic. Health Place 18(6):1404-1411. https://doi. org/10.1016/j.healthplace.2012.07.005

Blanchet K (2015) Thinking shift on health systems: from blueprint health programmes towards resilience of health systems. Int J Health Policy Manag 4(5):307-309. https://doi.org/10.15171/ijhpm.2015.49

Business Insider (2020) Amid govt efforts to increase COVID bed numbers, hospitals face shortage of health workers. Business Insider. https://www.businessinsider.in/india/news/amid-govt-efforts-toincrease-covid-bed-numbers-hospitals-face-shortage-of-health-workers/articleshow/76624090.cms. Accessed 30 July 2020

CDC (2018) Past pandemics. https://www.cdc.gov/flu/pandemic-resources/basics/past-pandemics.html. Accessed 30 July 2020

Chandler C, Fairhead J, Kelly A, Leach M, Martineau F, Mokuwa E, Parker M, Richards P, Wilkinson A (2015) Ebola: limitations of correcting misinformation. The Lancet 385(9975):1275-1277. https:// doi.org/10.1016/S0140-6736(14)62382-5

Chatterjee PK (2020) Community preparedness for COVID-19 and frontline health workers in chhattisgarh. Indian J Public Health 64(6):102. https://doi.org/10.4103/ijph.IJPH_467_20

Gostin LO, Friedman EA (2015) A retrospective and prospective analysis of the west African Ebola virus disease epidemic: robust national health systems at the foundation and an empowered WHO at the apex. The Lancet 385(9980):1902-1909. https://doi.org/10.1016/S0140-6736(15)60644-4

Government of India (2020) Ayushman Bharat Pradhan Mantri Jan Arogya Yojana. https://pmjay.gov.in/ hospital/covid19. Accessed 30 July 2020

Hanefeld J, Mayhew S, Legido-Quigley H, Martineau F, Karanikolos M, Blanchet K, Liverani M, Mokuwa EY, McKay G, Balabanova D (2018) Towards an understanding of resilience: responding to health systems shocks. Health Policy Plan 33(3):355-367. https://doi.org/10.1093/heapol/czx183

Indian Express (2020) Private hospitals charging hefty fees, claim Kin of COVID-19 patients. The New Indian Express. https://www.newindianexpress.com/cities/delhi/2020/may/26/private-hospitalscharging-hefty-fees-claim-kin-of-covid-19-patients-2148104.html. Accessed 30 July 2020

Karanikolos M, Mladovsky P, Cylus J, Thomson S, Basu S, Stuckler D, Mackenbach JP, McKee M (2013) Financial crisis, austerity, and health in Europe. Lancet (London, England) 381(9874):13231331. https://doi.org/10.1016/S0140-6736(13)60102-6

Khun A (2020) What lies behind Japan's successful management of the pandemic. NPR.Org. https:// www.npr.org/2020/05/26/862654095/what-lies-behind-japans-successful-management-of-thepandemic. Accessed 30 July 2020

Krishnan A, Dasgupta R (2020) Science, policy, people, and public health: what is COVID-19 teaching us? Indian J Public Health 64(6):87. https://doi.org/10.4103/ijph.IJPH_540_20

Kruk ME (2008) Emergency preparedness and public health systems lessons for developing countries. Am J Prev Med 34(6):529-534. https://doi.org/10.1016/j.amepre.2008.02.012

Kruk ME, Michael Myers S, Varpilah T, Dahn BT (2015) What is a resilient health system? Lessons from Ebola. The Lancet 385(9980):1910-1912

Lusignan S, Dorward J, Correa A, Jones N, Akinyemi O, Amirthalingam G, Andrews N et al (2020) Risk factors for SARS-CoV-2 among patients in the Oxford royal college of general practitioners research and surveillance centre primary care network: a cross-sectional study. Lancet Infect Dis. https://doi.org/10.1016/S1473-3099(20)30371-6

Mayhew S, Hanefeld J (2014) Planning adaptive health systems: the climate challenge. The Lancet Glob Health 2(11):e625-e626. https://doi.org/10.1016/S2214-109X(14)70313-4

McKee M, Karanikolos M, Belcher P, Stuckler D (2012) Austerity: a failed experiment on the people of Europe. Clin Med (London, England) 12(4):346-350. https://doi.org/10.7861/clinmedicine.12-4-346

Normile D (2020) Coronavirus cases have dropped sharply in South Korea. What's the secret to its success. Science 17(03):1-2 
Oosterhoff P, Mokuwa EY, Wilkinson A (2015) Community-based Ebola care centres: a formative evaluation I Ebola response anthropology platform. http://www.ebola-anthropology.net/case_studies/commu nity-based-ebola-care-centres-a-formative-evaluation/. Accessed 30 July 2020

PIB (2020) Health and wellness centres. www.pib.gov.in/Pressreleaseshare.aspx?PRID=1602355. Accessed 30 July 2020

Sadanandan R (2020) Kerala's response to COVID-19. Indian J Public Health 64(6):99. https://doi. org/10.4103/ijph.IJPH_459_20

Sharma NC (2020) India faces shortage of nurses as it fights to keep Covid-19 in check. Livemint. https ://www.livemint.com/news/india/india-faces-shortage-of-nurses-as-it-fights-to-keep-covid-19-in-check $-11589134989070 . h t m l$. Accessed 30 July 2020

Sundararaman T (2020) Health systems preparedness for COVID-19 pandemic. Indian J Public Health 64(6):91. https://doi.org/10.4103/ijph.IJPH_507_20

Sundararaman T, Mukhopadhyay I, Muraleedharan VR (2016) No respite for public health. Econ Polit Wkly 51(16):39-42

The Economic Times (2020) Mass testing, empty ICUs: Germany scores early against virus—ET health world. ETHealthworld.Com. https://health.economictimes.indiatimes.com/news/diagnostics/mass-testi ng-empty-icus-germany-scores-early-against-virus/74940919. Accessed 30 July 2020

The Economist (2020a) The 90\% economy that lockdowns will leave behind. The Economist. https://www. economist.com/briefing/2020/04/30/the-90-economy-that-lockdowns-will-leave-behind. Accessed 30 July 2020

The Economist (2020b) Vietnam and the Indian state of Kerala curbed Covid-19 on the cheap. The Economist. https://www.economist.com/asia/2020/05/09/vietnam-and-the-indian-state-of-kerala-curbe d-covid-19-on-the-cheap. Accessed 30 July 2020

The Economist (2020c) The pandemic has spawned a new way to study medical records. The Economist. https://www.economist.com/science-and-technology/2020/05/14/the-pandemic-has-spawned-a-newway-to-study-medical-records. Accessed 30 July 2020

The Guardian (2020) How will the world's poorest people get a coronavirus vaccine? I Achal Prabhala and Kate Elder. The Guardian. https://www.theguardian.com/commentisfree/2020/jun/24/worlds-poorestpeople-coronavirus-vaccine-gavi. Accessed 30 July 2020

The Hindu (2020a) Coronavirus : only 2,132 availed or being treated for COVID-19 under Ayushman Bharat Scheme. The Hindu. https://www.thehindu.com/news/national/only-2132-availed-or-being-treat ed-for-covid-19-under-ab-pmjay/article31635083.ece. Accessed 30 July 2020

The Hindu (2020b) Private hospitals flouting price caps for COVID-19 treatment. The Hindu. https://www. thehindu.com/news/cities/Delhi/private-hospitals-flouting-price-caps-for-covid-19-treatment/artic le32193621.ece. Accessed 30 July 2020

UN (2020) Modernizing our public health systems to be ready for the next pandemic. United Nations. https ://www.un.org/en/un-chronicle/modernizing-our-public-health-systems-be-ready-next-pandemic. Accessed 30 July 2020

WHO (2007) Everybody's business-strengthening health systems to improve health outcomes: WHO's framework for action. World Health Organization, Geneva

WHO (2008) International health regulations (2005). World Health Organization, Geneva

WHO (2020a) Coronavirus diseases (COVID-19) pandemic. https://www.who.int/emergencies/diseases/ novel-coronavirus-2019. Accessed 30 July 2020

WHO (2020b) 73rd world health assembly A73/CONF./1; Agenda Item 3. https://apps.who.int/gb/e/e_ wha73.html. Accessed 30 July 2020

Yamunan S (2020) Fear of Covid-19 spread makes private hospitals turn away patients - or charge them higher bills. https://scroll.in/article/959727/fear-of-covid-19-spread-makes-private-hospitals-turnaway-patients-or-charge-them-higher-bills. Accessed 30 July 2020

Publisher's Note Springer Nature remains neutral with regard to jurisdictional claims in published maps and institutional affiliations. 